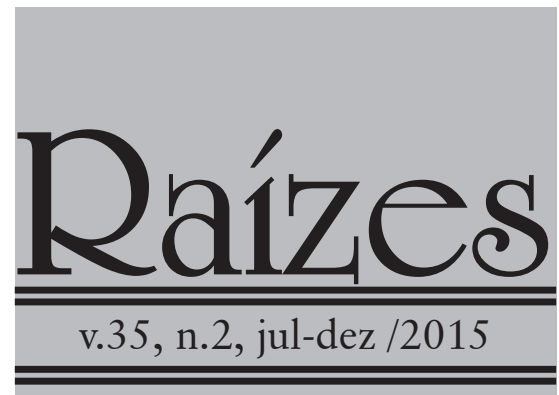

\title{
A CATEGORIZAÇÃO QUILOMBOLA E A SOCIOANTROPOLOGIA DO DESENVOLVIMENTO
}

\author{
Xavier Faure \\ RESUMO
}

Os processos de mudança social em comunidades quilombolas, podem ser estudados através da socioantropologia do desenvolvimento, tomada como uma perspectiva de análise para compreender o campo empírico e os efeitos sociais de programas de transformação social promovidos por instituições responsáveis pela implementação de políticas públicas às referidas comunidades. Esse trabalho procura descrever os efeitos das ações produzidas pela intervenção dessas políticas, através de uma etnografia em uma comunidade do sertão pernambucano reconhecida como quilombola. Conceitos da socioantropologia do desenvolvimento, em particular os de arena, conflito, norma e estratégia, auxiliaram na descrição da comunidade estudada, das interações, confrontos e colaborações entre as três famílias extensas envolvidas nos programas públicos de categorização étnica.

Palavras Chaves: Comunidades Quilombolas; Socioantropologia do Desenvolvimento; Políticas Públicas.

\section{THE CLASSIFICATION OF QUILOMBOLA AND THE SOCIOANTHROPOLOGY OF DEVELOPMENT}

\section{ABSTRACT}

Processes of social change in quilombola communities can be studied through the Socioanthropology of development, approach from which one interprets, at the empirical field, the social effects of the implementation of public policies referred to the cited communities. This work searches to describe theses effects through an ethnography in a community of Pernambuco's hinterland which was recognizedas quilombola. Concepts of socioanthropology of development, particularly those of arena, conflict, norm and strategy, helped us to describe the interactions, collaborations and confrontations between the three extended families of the community involved in public programs of ethnic categorization.

Key words: Quilombola communities; Socio-anthropology of Development; Public policies.

Doutorando em Ciências Sociais pelo Programa de Pós-Graduação em Ciências Sociais da Universidade Federal de Campina Grande. E-mail: xavfaure@hotmail.com. 


\section{INTRODUÇÃO}

A socioantropologia do desenvolvimento, ao "ancorar-se nos heterogêneos mundos da vida (Lebenswelten) de seus participantes" (Bierschenk, 2007, p. 8) e ao estudar como esses atores, alvos iniciais de operações de mudança social, tornam-se seus protagonistas, constitui uma perspectiva relevante para entender dinâmicas de transformação do mundo rural brasileiro. A contribuição dessa perspectiva antropológica, no Brasil, não se resumiria apenas aos programas de desenvolvimento rural, mas pode se estender, por exemplo, à análise dos efeitos sociais das categorizações étnicas, em particular, quilombolas.

Ao considerar a categoria quilombola no seu aspecto político, jurídico e administrativo, a abordagem que propomos parte do protagonismo do poder público para chegar ao protagonismo dos atores locais. Os referidos atores, beneficiários potenciais de políticas de categorização étnica, tornam-se sujeitos sociais ao se reapropriarem das categorias oficiais. Operamos, portanto, uma inversão em relação às abordagens mais comuns sobre comunidades quilombolas, as quais adotam a terminologia quilombola como conceito analítico ${ }^{1}$, de modo a identificar sujeitos étnicos latentes (cuja realidade étnica é ocultada, não manifesta), os quais são levados a acionar, posteriormente, as categorizações étnicas do poder público.

À luz de nossa inversão analítica, o nexo entre a antropologia do desenvolvimento e o estudo do efeito das categorizações étnicas torna-se mais claro. Isto porque a antropologia do desenvolvimento parte também do protagonismo dos atores externos, ao considerar o desenvolvimento como:
(...) o conjunto dos processos sociais induzidos por operações voluntaristas de transformação de um meio social, empreendida através de instituições ou atores exteriores a esse meio, e baseada numa tentativa de "transplante" de recursos, técnicas e/ou saberes² (Bierschenk apud Olivier de Sardan, 2007, p. 8).

As categorizações étnicas, ao empreenderem a nomeação de grupos, os quais são levados a acionar identidades ${ }^{3}$, parecem, de fato, obedecer à mesma lógica de operações de desenvolvimento, tentando transplantar técnicas e saberes em seus públicos alvos. Assim, em nosso entendimento, as categorizações étnicas - tal como os programas de desenvolvimento - são processos de ordenamento social que um conjunto de atores públicos (ou religiosos, acadêmicos e da sociedade civil) tenta promover entre populações rurais.

No entanto, essas intervenções externas conduzem ao protagonismo dos públicos alvos. Os atores locais dão sentido às categorizações étnicas ou às operações de desenvolvimento, mobilizando-as de acordo com seus modos de vida, interesses e circunstâncias em que ocorrem as intervenções. Tais dinâmicas de reapropriação manifestam-se em ações individuais ou agenciamentos coletivos, colaborações ou confrontos, demonstração de passividade ou de grande interesse, rumores, fofocas e conjecturas, ou discursos explícitos, retóricas eloquentes e rituais performáticos... Temos aqui, em suma, uma complexa teia de pensamentos e comportamentos que se entrelaçam e se transformam, estando sujeitos ao olhar e à avaliação dos outros, vizinhos ou parentes, engajados (ou arrastados) na mesma trama de um projeto de transformação social.

A complexidade dos processos requer uma abordagem empírica e interacionista, tal

\footnotetext{
1 Com relação ao uso do conceito analítico de quilombola, ver Arruti (2006), Almeida (2002) e Leite (2000).

2 Tradução oriunda do francês do próprio autor deste artigo, da mesma forma que todas as próximas citações de autores da socioantropologia do desenvolvimento.

3 Como a Constituição Brasileira define o critério da auto-atribuição no reconhecimento das populações quilombolas, poderse-ia objetar que o processo de construção identitária é fruto do protagonismo dos próprios atores locais, e não dos atores externos. Porém, em nossa visão, os processos de auto-reconhecimento são impulsionados pelo poder público, o qual, ao divulgar suas políticas de recorte étnico, incentiva determinadas comunidades - ou agentes mediadores dessas comunidades a acionarem a identidade quilombola.
} 
como promove a socioantropologia do desenvolvimento. $\mathrm{O}$ empirismo aqui não é uma ideologia exaltando o conhecimento pela descoberta da realidade local, mas um esforço analítico tendo como referência os comportamentos, agenciamentos e pontos de vista dos atores (Bierschenk, 2007). O interacionismo, nessa perspectiva, seria uma atenção conferida às estratégias e as margens de manobra dos atores, sem, no entanto, desconsiderar a coerção exercida pelos contextos socioeconômicos.

$\mathrm{Na}$ abordagem adotada, os efeitos das categorizações étnicas serão analisados na comunidade rural de Angico $^{5}$, situada no município de São Felipe, sertão de Pernambuco. Tendo recebido, em 2006, seu reconhecimento oficial como remanescente de quilombolas, a comunidade se tornou, pela atribuição identitária que lhe foi imposta, um palco de confrontos entre as três famílias extensas da localidade. Após uma fase inicial de traduções da categoria quilombola, as famílias, movidas por lógicas heterogêneas, posicionaram-se de maneira diversa para tirar proveito (ou limitar os efeitos) das políticas quilombolas.

O palco das interações entre as três famílias representa, nos conceitos da socioantropologia do desenvolvimento, uma arena local que, nos programas de mudança social, “[...] não funciona na base de um consenso social negociado, mas através de interações entre interesses (grupos), níveis de saberes locais, estratégias, normas, conflitos, compromissos e 'cessar-fogo'” (Bierschenk, 2007, p. 10).

Além da noção de arena, refletiremos sobre outras categorias provenientes da socioantropologia do desenvolvimento, em particular, a categoria conflito - hipótese de trabalho mais produtiva do que postular a existência do consenso (Olivier de Sardan, 1995) - além das noções de estratégia e normas, que pensam a atuação coletiva de grupos acionando representações sociais diversas.
Ao longo do processo de categorização étnica, tentaremos responder às seguintes indagações: a primeira, relacionada à hipótese de que o protagonismo inicial do poder público consiste em demonstrar em que medida a escolha de uma identidade quilombola corresponde a uma atribuição fortemente sugerida por atores governamentais; a segunda indagação, por sua vez, consiste em identificar as lógicas, estratégias e representações dos atores envolvidos na trama quilombola.

$\mathrm{Na}$ primeira parte do artigo descrevemos o impulso inicial da categorização étnica, resultando na imputação da identidade quilombola, cuja autoria vem de atores governamentais militantes. $\mathrm{Na}$ segunda parte, veremos que a atribuição dos militantes deu lugar a uma arena local, inicialmente marcada pela inércia, mas que depois entrou numa fase de maturação, correspondendo ao momento em que os atores deram um sentido mais explícito à categoria quilombola, tema que será desenvolvido da terceira parte do artigo. Concluiremos, elucidando em que medida os atores locais se posicionaram de modo mais claro, ao adotar estratégias diferenciadas.

\section{IMPUTAÇÃO DE IDENTIDADES}

A comunidade de Angico conta com aproximadamente 40 famílias nucleares, divididas em três famílias alargadas, os Oliveira, os Bastos e os Azevedo.

Chamados pelos outros durante muito tempo de "Negros do Angico", os Oliveira são os mais numerosos na comunidade (em torno de 25 famílias nucleares). Eles descendem de uma fratria de 11 irmãos moradores de uma grande fazenda, que adquiriram, nos anos 1930, em troca de serviço, uma gleba de 46 braças de terra ${ }^{5}$. Um fato importante é que a fazenda onde os Oliveira moravam e a terra que eles adquiriram não pertenciam a uma família do Angico: o grupo tinha mudado pa-

\footnotetext{
4 Os nomes das comunidades, dos municípios e das famílias que aparecem neste trabalho foram alterados.

5 As braças (uma braça equivale a 2,2 metros) correspondem à largura da propriedade, de 130 metros. A terra adquirida, muito estreita, tinha uma extensão bem maior, contabilizando uma superfície total de 60 hectares.
} 
ra a futura comunidade sem laços particulares de moradia, ou de compra de terra, com os outros grupos locais que comporiam a trama quilombola.

Os 11 irmãos Oliveira, quando se mudaram para a sua nova propriedade, batizaram-na de Angico, em referência a um espécime imenso desta árvore, onde havia um poço que abastecia a família. A fonte de água, no entanto, era situada na propriedade dos Azevedo, família que dispunha de quase todas as terras das adjacências.

Com o passar do tempo, a família Oliveira cresceu, através da endogamia e também da união com mulheres de fora, em particular, mulheres caboclas, as quais eram percebidas como mulheres da caatinga, lindas de cabelo liso ${ }^{6}$, mas não civilizadas. Os homens deveriam pegá-las a dente de cachorro para poder se casar com elas.

Embora alguns Oliveira, nas gerações seguintes, comprassem pequenos lotes de terra, os novos lares, em geral, confinaram-se à gleba original de 130 metros de largura, muito estreita para sustentar todos, ou seja, as 25 famílias nucleares, que atualmente se dividem em uma propriedade de 60 hectares.

Outra família de Angico - os Bastos (10 núcleos familiares) - instalou-se na comunidade nos anos 1940. A chegada do grupo foi provocada pela expulsão de seu chefe, cuja mulher tinha se envolvido com o patrão da terra onde os Bastos trabalhavam e residiam. O caso teve uma forte repercussão e o patrão sedutor, além de humilhar seu morador, mandou pra correr toda a sua família. Os Bastos retiraram-se às pressas, em uma gleba comprada de um vizinho do patrão. A gleba - adquirida na base do sacrifício, pela venda de todo o gado da família - era do mesmo tamanho que a dos Oliveira, muito estreita, porém generosa em comprimento.

A pessoa que tinha vendido a gleba aos Bastos pertence à terceira família, já evoca- da nesta apresentação: os Azevedo. Possuindo também o poço que deu nome à comunidade e que fica próximo ao imenso angico, onde os Oliveira procuravam água, este grupo - composto de seis famílias que ainda vivem na comunidade - representa um ramo da família Pereira, a elite fundiária e política de São Filipe. Nas adjacências de Angico, o clã dos Azevedo monopolizava as terras onde os Bastos e os Oliveira trabalhavam em regime de diárias ${ }^{7}$.

Os Azevedo que permaneceram na terra, filhos naturais e "criados" - pessoas de condições mais humildes, que foram criadas com a família -, disporiam de propriedades menores e fragmentadas, devido ao crescimento demográfico das gerações. Nos dias atuais, os últimos ainda fixados na terra são, por assim dizer, empobrecidos, trata-se de três famílias nucleares que se enquadram agora na categoria de agricultor familiar, ao administrarem, na base do trabalho familiar, propriedades médias de um pouco mais de 50 hectares.

Mesmo empobrecidos, esses agricultores dispõem de um patrimônio fundiário que não se compara ao minifúndio dos Oliveira e dos Bastos. Ademais, a posse da terra, fonte de poder dos Azevedo, foi convertida em outras fontes de influência, em particular, na polícia estadual, profissão de três membros deste grupo. Os policiais, apesar de exercerem uma atividade urbana, mantêm um laço afetivo com suas terras. Nos fins de semana, deixando a cidade, eles se reúnem no sítio para se divertir e cuidar da roça e do gado. Um dos principais orgulhos do grupo é a reforma de um velho engenho familiar, que estava em ruínas e foi reconstruído, dando agora, uma vez por ano, uma rapadura muito apreciada.

Esta rápida apresentação demonstrou que os Azevedo, agricultores, policiais ou outros, dispõem de uma influência muito maior do que as demais famílias da comunidade. Todavia, as intervenções políticas federais, so-

6 As citações em itálico e entre aspas são dos próprios moradores da comunidade de Angico.

7 As principais atividades dos trabalhadores estavam ligadas à pecuária e ao plantio de algodão, a principal fonte de renda de Mirandiba até a década de 1980 do século XX. 
bretudo a partir dos anos 2000, começaram a questionar essa situação local profundamente desigual. A Fundação de Cultura Palmares (FCP), ao introduzir a categorização quilombola, teria um papel fundamental nessa dinâmica de mudança.

No ano de 2007, em Angico, a atuação da FCP produziu um forte impacto na comunidade, forte não pela duração dos acontecimentos ou pela impressão deixada no momento das intervenções, mas pela influência significativa que causaria no quotidiano das três famílias. Concretamente, o que marcaria a comunidade era a imputação oficial, pela FCP, de uma identidade quilombola aos comunitários, sem que as próprias famílias soubessem desta identidade que lhes fora imposta. A imposição, de fato, havia passado despercebi$\mathrm{da}$, a FCP permanecera apenas algumas horas na comunidade, tempo suficiente para realizar rápidas entrevistas com os Oliveira, sem, no entanto, divulgar seus objetivos, que eram de atestar, através de pareceres oficiais, a existência oficial de comunidades quilombolas.

Em suma, a entidade governamental havia realizado uma façanha, não só pela eficácia e rapidez de suas intervenções, mas também pelo seu caráter ilícito, causado pela extrapolação de suas competências oficiais. Vinculada ao Ministério da Cultura, a FCP tem apenas a responsabilidade de oficializar, através de um atestado, a existência de comunidades que já se reconhecem como quilombolas. A instituição não tem, portanto, o poder de impor aos comunitários uma identidade que eles não escolheram. Porém, o procedimento de imputação de identidade aconteceu em Angico e se repetiu em todas as outras comunidades investigadas pela $\mathrm{FCP}^{8}$, como se este fosse um modus operandi.

$\mathrm{O}$ ativismo da FCP, que, a partir de uma leitura rápida da realidade local, deu origem a um projeto político de transformação social, resultou na implantação, a partir de 2007, de políticas públicas de construção de moradias e infraestrutura hídrica nas comunidades nomeadas como quilombolas de São Filipe. Pelo seu envolvimento na certificação das comunidades, a FCP permitiu desbloquear a liberação dos primeiros programas governamentais, projetos cuja liberação dependia de sinais locais favoráveis, tais como a existência certificada e oficial de populações quilombolas.

Nessas dinâmicas, o protagonismo dos nomeados quilombolas foi bastante obliterado. Mas, rapidamente, as populações locais dariam sentido às categorizações étnicas e se posicionaram em consequência.

\section{A ATRIBUIÇÃO DE SENTIDO À CATE- GORIZAÇÃO QUILOMBOLA}

A palavra quilombola, quando inicialmente pronunciada pelos agentes da FCP, suscitava estranhamento entre os comunitários. Ninguém antes tinha ouvido falar naquele termo. E a palavra negra, associada ao novo termo, adquiria na fala dos agentes um significado positivo, enquanto usualmente designava, em tom de desprezo, os Oliveira, os mais morenos de todos em Angico.

O impacto quilombola não se restringia à valorização do fato de ser negro. Ele se estendia também a ações e benefícios tangíveis: algumas comunidades de pessoal moreno de São Filipe, agora quilombolas, receberiam casas do Governo Federal; e um projeto de capacitação do Ministério do Desenvolvimento Agrário, implantado por uma ONG local, para oferecer oficinas sobre agricultura e pecuária especificamente para os quilombolas.

Além disso, havia a possibilidade de participação em seminários e encontros, organizados por instituições públicas e ONGs, nos quais lideranças de várias comunidades de São Filipe e de Pernambuco trocariam experiências. Sabia-se melhor da realidade de outras populações, especialmente da maior comunidade quilombola da região, que já há alguns 
anos acionava sua identidade étnica, através de uma ONG local e de lideranças políticas da comunidade.

O quilombola ganhava, assim, uma concretude que, em Angico, provocaria divisões. Para a socioantropologia do desenvolvimento, tais divisões se materializam em uma arena, onde se confrontam atores heterogêneos cujos poderes, interesses e normas divergem. A arena é, dessa forma, o espaço onde cada grupo exerce a micro política, usando de suas capacidades respectivas (ativas ou passivas, de ação ou de perturbação, pública ou camuflada), diante das oportunidades conferidas por um programa (Olivier de Sardan, 1995).

Os confrontos, as colaborações ou negociações entre os atores remetem a suas capacidades de agência, suas margens de manobra dentro de coerções estruturais. Esse conjunto de dinâmicas individuais e coletivas é apreendido através da noção de estratégia, que não deve ser entendida em seu aspecto instrumental, sistêmico ou excessivamente racional, mas, ao contrário, no seu aspecto contextual e ambivalente, remetendo a representações/práticas instáveis e contingentes, manifestadas de acordo com as circunstâncias. Os atores, na "confluência de múltiplas racionalidades" (Olivier de Sardan, 1995), acionam, de modo explícito ou implícito, uma grande diversidade de normas que, em muitos casos, parecem contraditórias, mas que de fato refletem a complexidade da vida social, permeada por ambiguidades e ambivalências.

A socioantropologia do desenvolvimento, em uma perspectiva heurística, propõe a noção de conflito para penetrar na diversidade dos interesses, dos poderes e das normas que definem uma arena. Em Angico, o conflito, na sua gênese, fundamentar-se-ia nas questões de identidade, dos descritores e delimitadores étnicos que, na comunidade, são muito marcados: os Azevedo se dizem brancos, ou de uma mistura principalmente branca; os Oliveira são nomeados os "Negros de Angico" e, mesmo não apreciando essa denominação, terminam por incorporá-la; e os Bastos apontam suas origens caboclas, por serem parentes de famílias de um território indígena próximo à comunidade.

Os três grupos, a despeito de sua heterogeneidade, foram levados a se unir na trama quilombola que se desenrolaria na comunidade. Tal aliança forçada, primeiro desdobramento do conflito, foi causada pelo pertencimento dos três à associação comunitária, instituição através da qual são obrigatoriamente mediados todos os dispositivos políticos ligados à categoria quilombola ${ }^{9}$. No período inicial do processo, em 2007, uma pesquisa do Centro de Cultura Luiz Freire, realizada em Angico, já sugeria o enfrentamento de dificuldades ligadas à associação, às identidades e ao quilombola. Efetuada pela ONG, a entrevista com um 'Bastos', embora enfatizasse o consenso, subentendia possíveis embates:

[...] somos descendentes de índio, somos mestiço, negro, índio, branco. A gente tem mais sangue de índio... a gente já ficou com sendo de várias raças. Mas eles (os Oliveira) não. O território é onde fica as terras dos Oliveira, a gente fica como morador do quilombo, dentro do território quilombola, mas nós não somos quilombola. A gente sempre conviveu junto, temos atividades, nosso relacionamento é de uma forma boa, a nossa associação de agricultores é tudo junto, é como se fosse uma família só (Freire, 2008, p. 3).

Nessa narrativa, a aparição de uma hierarquização na categorização quilombola e de uma união no quadro associativo revela uma profunda contradição. A hierarquização viria do fato de que os Oliveira, de uma raça só, constituiriam a matriz do quilombo, enquanto os Bastos, com mais sangue indio, seriam sua 
extensão, ao integrarem como moradores um território estruturado pelos Oliveira. A união, ao contrário, remeteria à convivência intensa (como se fosse uma família só, tudo junto) corporificada na associação comunitária.

A contradição entre a união dos comunitários e as gradações étnicas - contradição na qual se integra um terceiro elemento, os Azevedo - parecia anunciar uma situação intricada, tensa, mas, ao mesmo tempo, atrativa. A perspectiva dos recursos do governo e a confusão sobre seus modos de alocação fizeram com que a comunidade se tornasse menos um espaço de consenso e de convivência do que uma arena onde se esboçam posicionamentos e relações de força, aspirações e receios, atitudes de busca de melhoria e atitudes defensivas.

$\mathrm{Na}$ arena que se constitui, a associação materializa as tensões porque nela se conjugam as questões de recursos, mas também de identidades. Com efeito, não seriam apenas os bens materiais que transitariam pela entidade, mas também as mudanças de identidade. No final de 2010, a associação se tornou oficialmente quilombola, em seu nome e estatuto, a fim de responder às exigências do governo para acessar seus programas de recorte étnico, tal como o Projeto de Integração do Rio São Francisco ${ }^{10}$ (voltado à construção de pequenos sistemas de abastecimento de água), o poder público requeria das entidades locais um nome devidamente étnico. Sem o epíteto quilombola, as associações comunitárias locais não poderiam receber o programa, que já estava em fase de implantação nacional.

Quando souberam do imperativo governamental, os Bastos, e ainda mais os Azevedo, manifestaram sua oposição. Muitos não queriam se tornar quilombolas pelo viés da associação, mesmo com a perspectiva de benefícios! Mas, ao mesmo tempo, outros associados, inclusive alguns brancos e caboclos, alegavam que o interesse de todos era aceitar as exigências do governo para poder acessar suas políticas públicas.

As divergências que se manifestavam e que se desdobravam em muitos aspectos não pareciam ter solução. Corria-se o risco de perder o programa. A resolução do impasse veio então da mediação realizada pelo presidente do Conselho Municipal de Desenvolvimento Rural, liderança carismática que dispunha de uma grande influência sobre as populações rurais. O presidente do conselho evocou o acesso a políticas públicas, o protagonismo da população rural para acessá-las e o aspecto consensual das políticas quilombolas, as quais, nos termos da liderança, visavam auxiliar aos mais pobres, geralmente descendentes de moradores, sem prejudicar, entretanto, seus vizinhos apenas mais ricos, pequenos agricultores como os outros. Em suma, os aspectos assistencialistas das políticas (acesso à água, moradias) eram mais evocados, enquanto os mais polêmicos (a questão fundiária) eram ocultados.

Os associados, mesmo não convencidos das explicações, entenderam que as divisões internas poderiam prejudicar a efetivação do programa público. A assembleia geral dos associados ratificou, assim, a transformação do nome da associação, a qual ganhou o epíteto de "remanescente quilombola".

No seio de uma associação agora étnica, criada na expectativa de acessar o Projeto São Francisco, os termos dos embates se resumiram inicialmente aos benefícios do tipo assistencialista, como o acesso à água ou a moradias. A lógica que prevalecia entre os associados - em particular, os Bastos e os Azevedo - era a do direito prioritário atribuído aos que pagam escrupulosamente suas mensalidades. Os bons pagadores - ao contrário dos maus, como muitos dos Oliveira - teriam a prevalência sobre os recursos transferidos pelo governo. Outra lógica, compartilhada pela maioria dos Oliveira, era a de que o direito aos benefícios caberia aos associados que se dizem ne-

10 O nome completo do programa é: Projeto de Integração do Rio São Francisco com bacias hidrográficas do Nordeste Setentrional (PISF). 
gros, e não aos demais, independentemente de quem paga ou não as mensalidades.

Tais dilemas, que revelam dinâmicas de tradução local da categoria quilombola, mobilizaram as normas sociais das famílias. A questão das normas - sociais, oficiais e práticas importa muito para a socioantropologia do desenvolvimento, porque informa sobre as representações dos atores e suas estratégias. Os comunitários de Angico, pouco esclarecidos sobre as normas oficiais promovidas pelo governo, havendo instituído o que é a etnia, a etnicidade, os direitos sociais e o protagonismo social, fizeram uso de suas normas sociais para poder construir um entendimento próprio da categoria quilombola.

Para um autor como Olivier de Sardan (2015, p. 6), as normas sociais "prescrevem, proíbem e legitimam [...], se inscrevem em retóricas públicas [...] e são ensinadas". Trata-se, em suma, de formas explícitas de regulação da vida social, produzidas na esfera privada, mas que influem na vida pública, como, por exemplo, na gestão da associação de Angico.

$\mathrm{Na}$ trama quilombola que se estabelecia na comunidade, essas normas eram, por exemplo, os descritores étnicos produzidos pelas famílias, os quais, ensinados de geração em geração pelas histórias das famílias contadas aos mais jovens, evocam fatos familiares portadores de sentido ou valores morais vetores de comportamentos adequados. Outras normas se relacionam ao associativismo, ou seja, à ação coletiva pautada em direitos e deveres, que dá acesso a bens e recursos para quem é engajado nos processos.

Com a intervenção da FCP, e ainda mais com a perspectiva do Projeto São Francisco, essas classificações diversas e intricadas foram mobilizadas: os comunitários basearam-se nelas para construir normas práticas que, na socioantropologia do desenvolvimento, são formas implícitas de regulação da vida social, derivando das normas sociais das populações e das normas oficiais das instituições públicas (Olivier de Sardan, 2011).

A norma prática, em suma, representa um arranjo local tácito, mas que pode ser con- testado e remodelado pelos atores. Em Angico, antes de a associação ser rebatizada, as famílias representavam o quilombo como sendo dos Oliveira, porque as instituições como a FCP solicitavam-nos por eles serem negros e descendentes pobres de moradores. Aquele entendimento implícito da situação ocasionou um reflexo na associação. Ao término de suas reuniões mensais, quando o assunto recaía sobre questões quilombolas, os Oliveira - que tinham uma de suas lideranças como presidente da associação - organizavam momentos paralelos em que conversavam, entre eles, sobre os referidos assuntos.

Porém, com a transformação da associação, em associação quilombola, aumentaram as contestações: no momento das reuniões, os Bastos e os Azevedo começaram a acusar os Oliveira de fazer tudo entre eles, ou de querer puxar todos os benefícios para eles. O quilombola, ainda vinculado ao fenótipo negro dos Oliveira, relacionava-se também cada vez mais às questões da associação, ou seja, da ação coletiva dos comunitários para conseguir benefícios e melhorias. Os debates tornavam-se, desse modo, mais acirrados, o que marcaria um sinal de breves mudanças na forma de organização da associação.

Em 2011, as tensões, até agora difusas ou confinadas ao bate-boca entre as famílias, atingiram um estado muito mais grave, ligado ao surgimento da questão da terra. A terra estava, desde o início da trama quilombola, relegada à imaginação dos comunitários, talvez por receio de falar dela, mas também por falta de conhecimento. Com efeito, as famílias não sabiam como se daria concretamente a questão fundiária e as poucas informações que circulavam, através das instituições ou das outras comunidades, eram mais rumores e conjecturas vagas do que elementos concretos e tangíveis. Mas, com o evento que chegaria a terra, ocuparia o primeiro lugar nas preocupações dos comunitários.

O evento deflagrador ocorreu até de maneira fortuita, durante a execução do Projeto São Francisco que, lembramos, não tinha como meta a regularização fundiária, mas ape- 
nas a construção de um poço de abastecimento de água potável. Os acontecimentos, mais precisamente, ocorreriam durante uma oficina de mapeamento participativo, etapa de diagnóstico realizada pelo programa antes de perfurar o poço e que visava conhecer, através da narrativa das famílias, a realidade geográfica, social e econômica de Angico. A realização dessa oficina requeria, além do desenho de um mapa comunitário (realizado pelos Oliveira e Bastos), uma segunda etapa chamada de caminhada, ou seja, uma visita in situ, conferindo aos referidos locais da comunidade as realidades expressas no mapa dos comunitários.

Foi assim que, depois de terem percorrido alguns quilômetros e visitado algumas propriedades, os agentes do governo encontraram um membro dos Azevedo com o qual iniciariam uma pequena conversa, indagando-lhe sobre os limites de Angico com o lugar chamado Fazenda Nova, que representava o limite da comunidade, segundo os desenhistas do mapa. Surpreendido pela pergunta, o Azevedo respondeu de forma amável, juntando palavras aos gestos, ao apontar as árvores marcando a divisa. Ele não tinha então solicitado de seus interlocutores esclarecimentos sobre o motivo da caminhada e de suas indagações. Tinha restringindo sua fala ao que presumia que os agentes precisavam saber. Contudo, ao contar o acontecimento aos seus parentes algumas horas depois, acendeu-se um sistema de conjecturas, comentadas e aumentadas por todos, cujo tom de profecia alarmista espalhou-se com mais força que o fogo na caatinga: o rumor que circulava e se ampliava era que o governo pretendia mandar os quilombolas tomar a terra dos brancos!.

Nos meses seguintes ao acontecimento, Angico tornou-se palco de uma demonstração de força por parte dos Azevedo, que faziam alusões difamatórias - e pior, ameaçadoras - às duas outras famílias da comunidade. As pressões não eram sempre diretas, manifestando-se, em certos casos, de modo insidioso, através de comentários propagados na cidade de São Filipe, que ampliavam a questão, tornando-a pública, conhecida das demais famílias do munícipio. Sabia-se do caso, e os primeiros interessados, os Bastos e, sobretudo, os Oliveira, recebiam por meio de terceiros recados sobre os humores dos Azevedo.

A presidente da associação comunitária, da família Bastos e eleita em 2010 (sucedendo um Oliveira), era, no entanto, submetida à coação direta. Os Azevedo a interpelavam, fazendo alusões sobre sua atuação atrevida como dirigente da associação, que teria conduzido às perturbações ocorridas na comunidade. A presidente, que tinha um laço quase familiar com os Azevedo, por ser comadre deles, constatou ainda mais o clima de insegurança quando soube que alguém dos Azevedo tinha apontado uma arma e disparado tiros no bar da comunidade, onde se encontravam membros dos Bastos: a discussão entre os clientes havia derivado na questão da terra e o Azevedo, que, na vida civil, era policial, teria reclamado contra os quilombolas, atirando tiros no teto do estabelecimento. Depois do ocorrido, a presidente solicitou uma visita do Instituto de Colonização e Reforma Agrária (INCRA) ${ }^{11}$.

O INCRA, junto à FCP, organizou então uma reunião na comunidade. Todas as famílias compareceram à escola local, onde se sentia a materialidade da tensão acumulada no decorrer dos eventos. Cada um escutou atentamente as explicações dos agentes públicos, que expuseram o sentido da política quilombola, assim como seus possíveis efeitos, tais como a demarcação e titulação de terras, além da concomitante indenização dos proprietários. As tensões continuaram permeando as exposições, sobretudo quando se falava de terra e da compra destas pelo governo para regularizar o quilombo. Alguém dos Azevedo soltou um comentário irônico, perguntando se por acaso, tinha uma placa de venda na sua terra. Outros dos Azevedo e das ou- 
tras famílias ficaram mais calados, mas, até o fim, o clima permaneceu pesado; cada grupo desconfiando do outro e os Azevedo desconfiando de todos, do governo, como também do seu público alvo, os quilombolas Oliveira e até Bastos. Uma vez concluída a reunião, as ideias e estratégias dos atores locais tornar-se -iam, assim, mais claras.

\section{COMO AS FAMÍLIAS REPRESENTAM O QUILOMBOLA}

Os Azevedo, que somente em Angico são donos de três glebas encravadas nas terras dos Oliveira e dos Bastos, consideram, em sua maioria, o quilombola como uma imposição do governo ameaçando seus interesses fundiários. Alguns deles visualizam no fato de os negros se submeterem às leis do governo um fator de divisões, em uma comunidade onde, historicamente, a convivência entre os grupos seria harmoniosa. Nos termos deles, as famílias de Angico sempre colaboraram entre si, em uma relação de boa vizinhança, os Azevedo propiciavam serviços aos Oliveira e Bastos nas suas terras e os ajudavam em caso de necessidade.

Contudo, hoje, o equilíbrio desmoronou, e até os mais idosos dos Oliveira, inconformados com a situação, confessariam aos Azevedo não quererem se apossar da terra alheia. Porém, a lógica implacável do governo predominaria e o quilombola representaria uma espada em cima da cabeça dos brancos, pois a demarcação territorial, suscetível de ocorrer a qualquer hora, confiscaria arbitrariamente suas terras, o seja, o fruto de seu trabalho e da sua dedicação, adquirido através dos esforços repetidos das gerações. A arbitrariedade do governo se conjugaria, nas falas de alguns Azevedo, como uma profunda injustiça, na medida em que a família não se considera rica ou favorecida, na trama quilombola, a luta seria de pequeno contra pequeno.

Outros membros dos Azevedo, que não se envolveram nas ameaças e confusões, expressam uma visão mais nuançada da realidade. Eles reconhecem a existência do precon- ceito racial: um deles lembra que, em seu casamento, um parente estendeu uma corda entre os convidados para separar, no momento de iniciar as danças, suas filhas brancas dos jovens morenos. A categoria quilombola, segundo essas pessoas, tem sua justificativa, mas é a sua operacionalização que gera problema, pelo fato de as famílias não se comunicarem entre si. Cada um quer puxar pro seu lado, sem negociar nada com os demais. As famílias teriam o costume de se isolar, o que resultaria em uma grande inércia. A prática da endogamia atestaria esse hábito improdutivo, ao criar uma pobreza de espírito, uma falta de visão. Nesse universo confinado, da desconfiança e do isolamento, o futuro dos Oliveira é considerado problemático, não só por razão da falta de abertura da família, mas, sobretudo, devido à falta da terra para sustentá-la.

Os Bastos, por sua vez, sofreram desde o início uma relegação simbólica, eles são identificados (e se identificam) como menos quilombolas que os Oliveira, apesar de compartilharem com eles características sociais parecidas em termos de acesso a terra e disponibilidade de recursos. Por outro lado, mesmo sendo mais pobres que os Azevedo, os Bastos compartilham com eles laços de consideração. As famílias compartilham o compadrio e essa consideração mútua remonta a um episódio já evocado: a expulsão dos Bastos da terra onde eram moradores e sua chegada a uma gleba comprada de um Azevedo. Aquele momento de aflição, lembramos, foi provocado pelo envolvimento da mulher do chefe dos Bastos com o patrão da terra onde a família morava. No tumulto criado pelo caso, os Bastos correram às pressas e foram acolhidos por um Azevedo, o qual cedeu a eles, por um preço supostamente baixo, a gleba onde os Bastos construiriam seu futuro.

O laço de consideração, como sugerem os eventos do passado e a situação do presente, é fortemente assimétrico. E é por isso que os Bastos são pressionados a desistir da ideia de se unir aos Oliveira, em um quilombo que os afastaria dos Azevedo e causaria até sua ira, além do desencadeamento de reações imprevisíveis. 
O dilema para os Bastos é grande, mas, afinal, o propósito quilombola é considerado digno de interesse, devido às opções oferecidas aos mais pobres. O quilombola traz benfeitorias às comunidades, não só em termos de acesso à água e a moradias, mas também influi na efetivação de políticas públicas que, como a aposentadoria rural e, em uma escala mais restrita, o Garantia Safra ${ }^{12}$, dependem da comprovação do uso de uma terra de tamanho compatível com a agricultura.

Os Bastos, na sua situação de minifúndio que se agrava com o crescimento demográfico, têm cada vez mais dificuldades em acessar esses direitos sociais vinculados à atividade agrícola. Segundo eles, o problema poderia ser resolvido ao se tornarem quilombolas, pois essa categorização os isentaria da obrigação de comprovar uma quantidade mínima de terra por beneficiário. O único requisito seria uma declaração atestando o pertencimento a um quilombo que disporia de seu próprio território. Portanto, o estatuto de quilombola adquire, pelo menos neste aspecto, um caráter emancipatório: libera da obrigação de se submeter aos proprietários maiores, que são solicitados para fornecer contratos de terra, documentos em parte fictícios usados para atestar o trabalho agrícola de uma pessoa em terra alheia. No caso dos Bastos, essa prática é percebida como humilhante, por levá-los a pedir favor aos Azevedo, os quais, em muitas situações, recusam-se a aprovar o pedido, mesmo quando ele vem de alguém que já trabalhou com eles como diarista.

Mas, diante dos benefícios potenciais da categorização quilombola, os possíveis prejuízos são grandes e advêm, sobretudo, da terra e dos Azevedo. Nas declarações da presidente (Bastos) da associação na época do auge das tensões (a pessoa não é mais presidente agora), o fato de as glebas dos Oliveira e Bastos não serem contíguas cria um problema. Para emendar as duas propriedades, seria necessário passar em duas glebas de Azevedo que não são agricultores, mas demonstraram opo- sição à ideia de ceder suas terras. Além da falta de contiguidade do possível território quilombola, as dificuldades provêm daqueles que estão em volta dos Oliveira e Bastos. Cercando as duas famílias, há um grupo do Azevedo agricultores e policiais que se mostra radicalmente oposto a uma possível extensão do quilombo.

$\mathrm{O}$ incômodo gerado pela categorização quilombola não advêm apenas dos Azevedo, mas também dos Oliveira. A convivência entre essa família e os Bastos é considera boa - $\mathrm{CO}^{-}$ mo se fosse uma família só, na narrativa citada anteriormente - mas, quando se sonda nos pormenores a relação, observam-se divergências recorrentes. A primeira associa-se à raridade das uniões afetivas entre as duas famílias. Foram somente três casamentos em 70 anos de convivência e, com o passar dos anos, cada grupo tendeu a praticar a endogamia ou a se unir com famílias externas à comunidade. Alguns dos Bastos interpretam esse fato sugerindo uma divergência mais geral associada à falta de abertura dos Oliveira. Tal propensão afetaria, aliás, todos os aspectos da vida comunitária, inclusive aqueles ligados à categorização quilombola. Os Oliveira, solicitados inicialmente para ingressar na categoria quilombola, imporiam sobre ela uma espécie de tutela, recusando-se a repassar para os Bastos as informações e, implicitamente, os recursos materiais, advindos dos programas para quilombolas.

Criticados pelas outras famílias, que reclamam de sua cultura do segredo e do confinamento, os Oliveira dizem encarnar a categoria quilombola. Eles foram os protagonistas inicias dessa trama - foi através deles que vieram as primeiras intervenções governamentais - e seriam eles, e unicamente eles, que materializariam a existência de uma etnia quilombola na comunidade. Os outros, ao contrário, teriam uma atitude oportunista, ao querer entrar no quilombola só para os benefícios.

Esses comentários, na verdade, advêm das lideranças, principalmente de uma jovem mulher que dirige uma nova associação na comunidade (falaremos mais adiante dessa no- 
va entidade). Quanto aos demais membros do grupo, eles demonstram uma atitude muito mais enigmática. Quando se trata do quilombola, eles se expressam de maneira lacônica, afetando certo distanciamento com as questões evocadas. Em algumas situações, parecem também se abrigar no governo, como se este fosse o único responsável pelas intervenções, o único dono da palavra que decide aquilo que deve ser feito. Mesmo na palavra da liderança, o governo desempenha o protagonismo maior, definindo as medidas, aplicando os recursos e delimitando os direitos dos diferentes atores envolvidos. $\mathrm{O}$ papel da liderança, nesse contexto, é de 'segurar a peteca', mantendo uma posição firme à espera das intervenções do governo.

\section{ESTRATÉGIAS}

Após as tensões de 2011, apenas os Oliveira sustentaram o processo de categorização quilombola. Os Bastos, através da presidente da associação na época, desistiram de levar adiante a transformação de Angico em quilombo. A frágil aliança entre as duas famílias, materializada na ideia dos Bastos de integrarem, como moradores, uma área quilombola cuja sede seria dos Bastos, desmoronou diante das ameaças dos Azevedo.

Os Oliveira, afinal, saem reforçados da fase de tumulto. Legitimados por se considerarem e, por serem considerados como os mais quilombolas, eles aumentaram sua legitimidade ao tomar conta do processo de categorização quilombola, cujo fundamento é a questão territorial, por meio das etapas de demarcação e titulação de terras.

Concretamente, a retomada dos Oliveira consistiu na criação, em 2013, de uma nova associação, batizada com o nome do fundador do clã - que tinha adquirido, em 1932, a terra onde seus filhos constituiriam suas famílias. Ao resgatarem o nome do patriarca, os Oliveira enraízam a nova entidade no patrimônio familiar: todos os associados - em torno de 30 são netos, bisnetos ou tataranetos do patriarca.
A associação, portadora do projeto quilombola, é dirigida pela jovem liderança evocada anteriormente. Essa pessoa articulase com outras lideranças quilombolas do município, faz parte do grupo que criou uma associação das comunidades quilombolas de São Filipe, a qual contribuiu para a implantação de políticas públicas de recorte étnico, como o Programa Nacional de Habitação Rural (PNHR), cuja transferência foi realizada sem intermediações locais - como prefeitura, conselho de desenvolvimento - envolvendo apenas atores quilombolas. No momento da redação deste trabalho, o projeto estava sendo executado, com a previsão da construção de 120 casas em três etapas. Quatro dessas casas estão sendo construídas em Angico, o que representa um evento inédito, pois, anteriormente, a comunidade não tinha recebido nenhum projeto desse tipo.

Outro aspecto da atuação da liderança é a regularização fundiária da parte da comunidade de Angico representada pela recémfundada associação dos Oliveira. O processo é demorado e ainda está em fase inicial, o pedido de demarcação territorial junto ao INCRA foi lançado apenas em 2014, pela intermediação de uma dirigente da associação quilombola de São Filipe. Antes de realizar esse pedido, a liderança dos Oliveira havia lutado para recuperar o precioso documento da FCP, de certificação de Angico como comunidade quilombola. O documento em questão estava nas mãos do presidente da associação matriz de Angico, um Azevedo. Como os dois lados não se comunicam e, de qualquer maneira, o Azevedo não entregaria a certificação, a liderança solicitou diretamente à FCP uma segunda via do documento, que logo foi enviada, para depois ser guardada meticulosamente na pasta de documentos da associação.

Afinal, o episódio da confiscação do atestado quilombola revela que os Azevedo, por meio do novo presidente da associação matriz, são mais implicados na gestão dos assuntos comunitários. Ciente de que os negros sabem ocupar os espaços, e que os brancos são ausentes das associações e do conselho de de- 
senvolvimento, o novo presidente, eleito em 2014, resolveu ocupar o espaço local de poder, enquanto anteriormente ele se desinteressava das atividades associativas. $\mathrm{O}$ momento de sua posse foi até favorável, por se situar após a dissidência dos Oliveira, que deixaram a associação para criar a sua própria entidade, a qual reivindicaria a regularização do quilombo. A associação matriz, recuperada pelos Azevedo, representaria, desse modo, o projeto oposto ao dos Oliveira, ou seja, o projeto de permanência de Angico como comunidade normal, não étnica.

Nessa associação livre do perigo quilombola, o Azevedo diz querer agir de forma diferenciada, pelo bem de todos, sem beneficiar seus parentes ou grupos de afinidade. Representando associados tanto dos Bastos como de uma parte dos Oliveira (em torno de um quinto deles), o novo presidente pretende correr atrás de projetos para todo o povo de Angico. Como demonstração disto, ele evoca um momento em que recusou a proposta do presidente do conselho de desenvolvimento, que queria colocá-lo na lista dos beneficiários de uma cisterna calçadão ${ }^{13}$. Em vez de ser beneficiado, em virtude de suas boas relações com o conselho de desenvolvimento, o Azevedo preferiu ceder a cisterna para um de seus associados, um Bastos muito necessitado.

A atenção concedida aos projetos leva o Azevedo a não lançar mão dos benefícios ligados aos quilombolas. Ele justifica essa procura pela lógica associativa evocada anteriormente, que reconhece aos associados em dia com suas mensalidades o direito de usufruir dos bens transferidos através da associação. Ao rememorar os tempos da associação única, em que os Bastos e os Azevedo pagavam suas contribuições (ao contrário de certos Oliveira), o novo presidente reafirma a legitimidade de seu grupo em usar um poço artesiano perfurado em 2014, no âmbito do Projeto São Francisco. Mais precisamente, sua alega- ção é que o referido poço, contrariamente ao que dizem os Oliveira, deverá abastecer, quando for equipado, todas as famílias da comunidade, e não apenas o grupo dos quilombolas.

É possível conjecturar que embates desse tipo serão numerosos nos anos vindouros. Em meio aos conflitos, os Bastos parecem procurar uma conciliação passiva, ao manter uma relação submetida aos interesses dos Azevedo. Desde as tensões de 2010, que resultaram na desistência da presidente Bastos da associação, aquela família não dispõe mais de lideranças capazes de influenciar o rumo das intervenções.

Sem latitude para orientar as ações de acordo com seus interesses, os Bastos dispõem de uma margem de manobra agora muito reduzida, a família parece está "entre a cruz e a espada", intercalada entre os Oliveira, parceiros enigmáticos e duvidosos na trama quilombola, mas encarnando um projeto promissor de emancipação étnica, e os Azevedo, compadres dominantes, representando a ordem estabelecida, o projeto de uma conformidade sem quilombolas nem promessas, mas também sem inseguranças.

\section{CONCLUSÃO}

Talvez o receio de uma deterioração na convivência comunitária - do tipo “a situação está ruim hoje, mas pode ainda ser pior amanhã" - possa explicar as incertezas e renúncias dos Bastos. Embora a trama quilombola possua uma vertente emancipatória, ela apresenta, no entendimento de alguns comunitários, um lado ameaçador, de atualização de laços de submissão, com os Oliveira substituindo os Azevedo como grupo dominante.

Aludimos aqui o caráter ambivalente da categoria quilombola, ambivalência que, afinal, é inerente a todo projeto de transformação social. No quadro dessa pesquisa, po-

13 Com capacidade para 40.000 litros, essa cisterna capta a água da chuva através de um espaço calçado de $200 \mathrm{~m}^{2}$. O projeto ao qual se refere o presidente da associação é do Programa Uma Terra e Duas Águas $(\mathrm{P} 1+2)$, implantado pelo Governo Federal através de uma rede de organizações da sociedade civil (a Articulação Semiárido brasileiro - ASA), de ONGs regionais e dos Conselhos Municipais de Desenvolvimento Rural. 
deríamos até imergir mais profundamente nas contradições dos processos. Um elemento que, por falta de tempo, não foi evocado é a tensão referente ao projeto socializante do quilombola. Ao promover, no futuro, a posse coletiva de territórios que atualmente são divididos em propriedades privadas (ou familiares, em um sentido lato), a categorização quilombola confunde alguns moradores das comunidades, que temem a perda da posse e gestão de sua terra num conjunto mais amplo e coletivizado.

O medo, aliás, não é tanto de um coletivo impessoal e igualitarista, mas de um coletivo que seria controlado por determinados grupos (em particular, familiares), tirando proveito de sua posição no topo da organização quilombola. Em suma, tal como os Bastos temendo a substituição de uma sujeição para outra, muitos comunitários parecem recear, no advento do quilombo, a substituição da dominação dos grandes proprietários para a dominação de grupos de afinidade que, muitas vezes, são seus congêneres, parentes ou vizinhos.

De fato, o parente ou a pessoa de mesma condição não seria necessariamente um aliado. Nossa pesquisa, ao considerar, devido à limitação de tempo, os grupos familiares de Angico de maneira genérica (na união de seus membros), não identificou todas as divisões e contradições permeando os próprios grupos. Assim, um trabalho mais aprofundado - pautado nos princípios de que os grupos “[...] não são sujeitos coletivos dotados de volição" (Olivier de Sardan, 1995, p. 51) - desenvolveria uma análise mais atenta às múltiplas racionalidades dos atores e aos antagonismos que podem vivenciar, inclusive no seio de células familiares alargadas.

Um ponto importante na análise dos atores e da arena é a questão das lideranças, que tendem a se tornar mediadoras entre o poder público e seus parentes na localidade. Fizemos referência, anteriormente, à atuação de lideranças Oliveira e Azevedo, mas poderíamos imergir de maneira mais detalhada nas construções de sentidos que esses intermediários operam na junção entre os mundos heterogêneos do poder público e dos comunitários.

E é justamente nessas junções que se faz necessário pensar as interconexões entre instituições federais e locais, sem esquecer os governos municipais - que não foram evocados neste artigo, mas que influenciam os processos. A arena, desse modo, não se restringe aos atores locais, aos seus confrontos e colaborações, mas se estende a outras formas de poder, em outras escalas, que constroem com os atores locais a trama da mudança social.

Ainda em relação à arena, outro elemento a ser considerado é o elemento diacrônico, o qual, na socioantropologia do desenvolvimento, é sempre presente, na medida em que a história do passado informa sobre as estratégias atuais dos atores. Em Angico, um olhar diacrônico instruir-nos-ia sobre a busca de autonomia dos Oliveira, que hoje se expressa pelo acionamento da identidade quilombola, mas que antigamente passava pela identidade índia. Nos anos 1950, com efeito, a família, em um período de expansão de uma área indígena situada próximo a Angico, procurava acionar sua indianidade, através do ritual do toré, dança que exalta a ligação carnal dos índios com a terra. Em torno desses rituais, poderíamos ter resgatado, pelas narrativas dos comunitários, as colaborações e tensões entre os atores. E teríamos constatado, afinal, que as lógicas das famílias - de autonomia dos Oliveira, de conciliação dos Bastos e de oposição dos Azevedo - tiveram um reflexo nas dinâmicas atuais.

O exercício efetuado, mesmo com suas limitações, revelou o "entrelaçamento de lógicas sociais” (Olivier de Sardan, 2007) que se manifesta em um projeto de categorização étnica. As noções de arena, conflito e estratégia contribuíram para revelar as dinâmicas ambíguas e entrelaçadas da mudança social em Angico. Lógicas familiares, lógicas associativas, de autonomia, de conciliação, de obstrução, lutas de classificações identitárias, lutas de influência se mesclam, esbarram-se e se cruzam para compor uma trama complexa. Nesta trama, as normas sociais relativas à identidade, 
à ação coletiva e também ao uso da violência regulam consideravelmente as interações, do mesmo modo que os arranjos locais promovidos pela prática e as normas oficiais agenciadas pelo poder público.

Afinal, o poder público, impulsionador das dinâmicas, continua tendo um papel primordial. Para as famílias, é ele que regulariza a questão fundiária, ao liberar recursos e definir os direitos de cada grupo. Os Oliveira, que poderiam influir no processo, ao definir a extensão de seu território, sentem o peso da reponsabilidade. Eles esperaram, assim, que o poder público assuma seu papel de guia e árbitro, ao mediar os conflitos e alocar recursos para se chegar a um consenso.

\section{REFERÊNCIAS BIBLIOGRÁFICAS}

ALMEIDA, Alfredo Wagner Berno. Os Quilombos e as Novas Etnias. In: O'DWYER, Eliane Canterino, organizadora. Quilombos: identidade étnica e territorialidade. Rio de Janeiro: Editora FGV, 2002. p. 43-81.

ARRUTI, José Mauricio Andion. Mocambo: antropologia e história dos processos de formação quilombola. Bauru (SP): Edusc/Anpocs, 2006.

BIERSCHENK, Thomas. Enchevêtrement des logiques sociales. Jean-Pierre Olivier de Sardan en anthropologue du développement. In: BIERSCHENK, T.; BLUNDO, G.; JAFFRÉ, Y.; TIDJANI ALOU, M. Orgs. Une anthropologie entre rigueur et engagement: Essais autour de l'oeuvre de Jean-Pierre Olivier de Sardan. Paris: APAD - Karthala, 2007, p.1-22.

FREIRE, Centro de Cultura Luiz. Mapeamento etnográfico das comunidades quilombolas do sertão de Pernambuco. Projeto inclusão social para populações Quilombolas em Pernambuco. Pesquisadora Sumaia Vieira. Olinda: CCLF, 2008.

LEITE, Ilka Boaventura. Os quilombos no Brasil: questões conceituais e normativas. Etnográfica, n.4, 2000, p.333-354.

OLIVIER DE SARDAN, Jean-Pierre. Anthropologie et développement: essai en socio an- thropologie $d u$ changement social. Paris: APAD, Karthala, 1995.

. De la nouvelle anthropologie du développement à la socio-anthropologie des espaces publics africains. Revue Tiers Monde, n.191, 2007, p.543-552.

. Practical norms: informal regulations within public bureaucracies (in Africa and beyond). In: DE HERT, Tom; OLIVIER DE SARDAN, Jean-Pierre. Real Governance and Practical Norms in Sub-Saharan Africa. Routledge: 2015. 